\title{
Uma abordagem para o ensino das cores para Daltônicos
}

\author{
Gerson R. Santos, Isledna R. Almeida, Rafaela G. Almeida, Zildomar C. Félix \\ Universidade Federal Rural de Pernambuco (UFRPE) \\ Caixa Postal 15.064 - 91.501-970 - Serra Talhada - PE - Brasil \\ gersonrs@live.com,\{rafaela.a93,isledna,zildomarf\}@gmail.com
}

\begin{abstract}
Intellectual development and cognitive processes children are able to understand shapes, colors, and make associations imagine. During this development games are educational tools that aid in children's learning, but in some cases we may have inappropriate games for children with a disability, especially colorblind. This work aims to present the development of a learning object for the help in teaching of colors to colorblind based in the universal design. The principles on which the game was modeled and developed a solution for the colorblind, and the elements used in the game will be presented.
\end{abstract}

Resumo. No desenvolvimento intelectual e processos cognitivos as crianças são capazes de entender formas, cores, fazer associações e imaginar. Durante esse desenvolvimento jogos educativas são as ferramentas que ajudam no aprendizado das crianças, porém em alguns casos podemos nos deparar com jogos inadequados para crianças com algum tipo de deficiência, em especial as daltônicas. Este trabalho tem como objetivo principal apresentar o desenvolvimento de um objeto de aprendizagem para o auxilio no ensino das cores para daltônicos baseado no design universal. Serão apresentados os princípios em que o jogo foi modelado e desenvolvido, uma solução para os daltônicos e os elementos utilizados no jogo.

\section{INTRODUÇÃO}

No mundo moderno em que vivemos, crianças já nascem em contato com a tecnologia e crescem juntos interagindo entre si, e isto é de grande ajuda no desenvolvimento da criança em geral, proporcionando meios mais rápidos, fáceis e eficazes de aprendizado e conhecimento para estes que, em uma idade pequena, são capazes de adquirir conhecimento rapidamente.

Piaget descreve essas e outras características como processos cognitivos. Em alguns casos, o aprendizado da criança não é atingido da forma esperada devido a algum tipo de deficiência. Apesar de haver mecanismos que auxiliam este aprendizado, em muitos casos nem sempre são utilizados ou não são adequados ou talvez nem existam. Ainda que a tecnologia esteja evoluída, há limitações para com o que se pode fazer para ajudar os deficientes, mas hoje a tecnologia consegue abranger quase todos os tipos de deficiência e uma conquista grande para os daltônicos foi a criação da linguagem das cores. 
Através dessa linguagem, foi possível desenvolver um objeto de aprendizagem para o auxilio no ensino das cores para daltônicos baseado no design universal.

\section{A TEORIA DE PIAGET}

Segundo Papalia, Olds e Feldman (2001), na teoria de Piaget, no segundo estágio do desenvolvimento cognitivo, que vai aproximadamente dos 2 aos 6 anos de idade, as crianças tornam-se mais sofisticadas no uso do pensamento simbólico. Apesar disto ainda não são capazes de pensar logicamente, o que só acontece no estágio das operações concretas. Piaget no período pré-operatório identificou vários progressos cognitivos, nomeadamente a função simbólica, a compreensão das identidades, a compreensão da causa e efeito, a capacidade para classificar, a compreensão do número, a empatia e a teoria da mente. E segundo Joana Vieira [s/d], durante o período préoperatório o pensamento sofre uma transformação qualitativa. Assim, as crianças não estão limitadas ao seu meio sensorial imediato. $\mathrm{O}$ ensino é quase desnecessário, pois a vantagem do modo intuitivo é que as crianças são capazes de livres associações, fantasias e significados únicos ilógicos.

\section{DALTONISMO}

Um dos problemas que não é percebido pela sociedade é o daltonismo (também chamado de discromatopsia ou discromopsia), que atinge cerca de $10 \%$ da população mundial sendo a grande maioria do sexo masculino, pois o problema está geneticamente ligado ao cromossomo $\mathrm{X}$, onde os homens possuem apenas um cromossomo $\mathrm{X}$, enquanto mulheres possuem dois cromossomos $X$ (Frank et al, 2011).

Daltonismo é uma perturbação da percepção visual caracterizada pela incapacidade de diferenciar todas ou algumas cores. Um individuo com visão normal é capaz de ver cerca de 30.000 cores. O daltônico apenas consegue identificar ou diferenciar entre 500 e 800 cores, manifestando-se muitas vezes pela dificuldade em distinguir o verde do vermelho. Esta perturbação tem normalmente origem genética, mas pode também resultar de lesão nos órgãos responsáveis pela visão ou de lesão de origem neurológica. Em muitos casos, o daltônico sente-se constrangido como por exemplo quando vai comprar algum vestuário e tem vergonha de pedir ajuda, causando além do constrangimento, dificuldade na sua integração social. A criança daltônica dificilmente é bem aceita no primeiro sintoma de daltonismo porque maior parte das vezes a culpa é do professor que não ensinou bem as cores e os pais não querem assumir que possam ter um filho que não é "perfeito". A criança daltônica algumas vezes é motivo de piada nas escolas, por exemplo, quando a mesma tem que pintar uma arvore, ela sabe que a arvore é verde mais olha para os lápis e não sabe qual é o verde, o daltônico não troca às cores, ele confunde (Miguel,2014).

\section{SOLUÇÃO}

Com o avanço da tecnologia é possível resolver varias das deficiências da humanidade, mas em contra partida o daltonismo não tem cura, mas nem por isso a solução é impossível. Atualmente existe o projeto COLORADD - sistema de identificação de cores para daltônicos (Figura 1). Usando as cores primarias, representadas através de 
símbolos simples, o código foi desenvolvido com base num processo de associação logica e de fácil memorização.

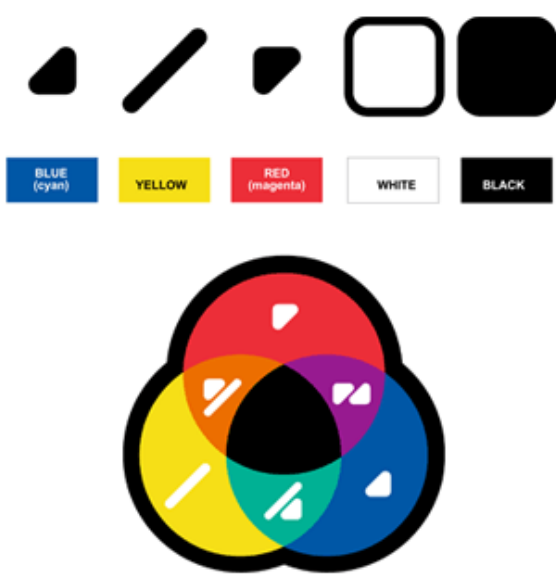

Figura 1- sistema de identificação de cores para daltônicos

\section{O DESIGN}

O design do aplicativo foi pensado para que crianças daltônicas pudessem interagir com o aplicativo e aprender as cores, mas não somente os daltônicos, mas como também qualquer criança poderá utilizar esse aplicativo para aprender as cores. Com isso o mesmo foi desenvolvido a partir do design universal.

Em 1987, o americano Ron Mace, arquiteto que usava cadeira de rodas e um respirador artificial, criou a terminologia Universal Design, Design Universal, Design Total ou Design Inclusivo. Mace acreditava que esse era o surgimento não de uma nova ciência ou estilo, mas a percepção da necessidade de aproximarmos as coisas que projetamos e produzimos, tornando-as utilizáveis por todas as pessoas. Na década de 90 , o próprio Ron criou um grupo com arquitetos e defensores destes ideais para estabelecer os sete princípios do desenho universal. Estes conceitos são mundialmente adotados para qualquer programa de acessibilidade plena. São eles: Igualitário, Adaptável, Óbvio, Conhecido, Seguro, Sem esforço e Abrangente (Carletto e Cambiaghi, [s/d]).

No Design Universal, o designer estuda uma série de questões que geralmente não são abordadas em um projeto comum. Neste trabalho ele precisa considerar todas as possibilidades de uso, por usuários muito diferentes. Isso inclui questões sociais, históricas, antropológicas, econômicas, políticas, tecnológicas, e principalmente de ergonomia e usabilidade.

\section{O JOGO}

Com características de jogo infantil, este projeto foi desenvolvido com personagens que prendem a atenção da criança, com animações que reagem de acordo com o andamento do mesmo e elementos que seguem ao longo do jogo e interagem com o usuário. $\mathrm{O}$ jogo é composto por um personagem principal, o Pluto, que tem o objetivo de estourar balões que existem dentro do jogo. A missão a ser cumprida pela criança é identificar a cor do balão maior que está no topo da tela, através do design universal, e fazer com que o personagem, Pluto, estoure o balão correspondente (Figura 2). 
CBIE-LACLO 2015

Anais do XXVI Simpósio Brasileiro de Informática na Educação (SBIE 2015)

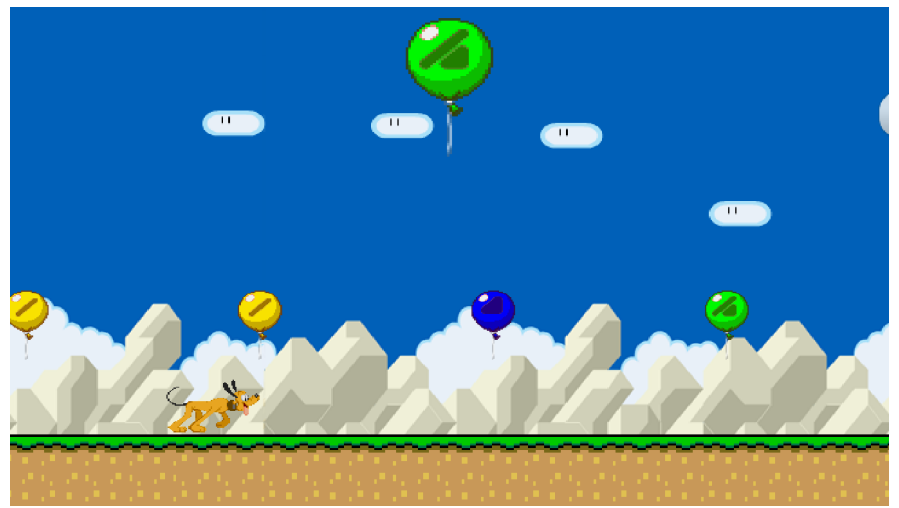

Figura 2- Tela do aplicativo

Os balões que passam pelo caminho do Pluto são os únicos que podem ser estourados. As crianças daltônicas vão aprender a identificar as cores através dos símbolos tornando mais fácil o aprendizado.

Para que a criança possa aprender qual a cor é a correta foi implementado no jogo um mecanismo de feedback para o usuário entender o que ouve e assim saber se errou ou acertou. Esse mecanismo é o próprio Pluto que muda suas feições dependendo de acerto ou erro. Caso pule no balão correto ele mostra uma animação de felicidade como mostra na figura 3 :

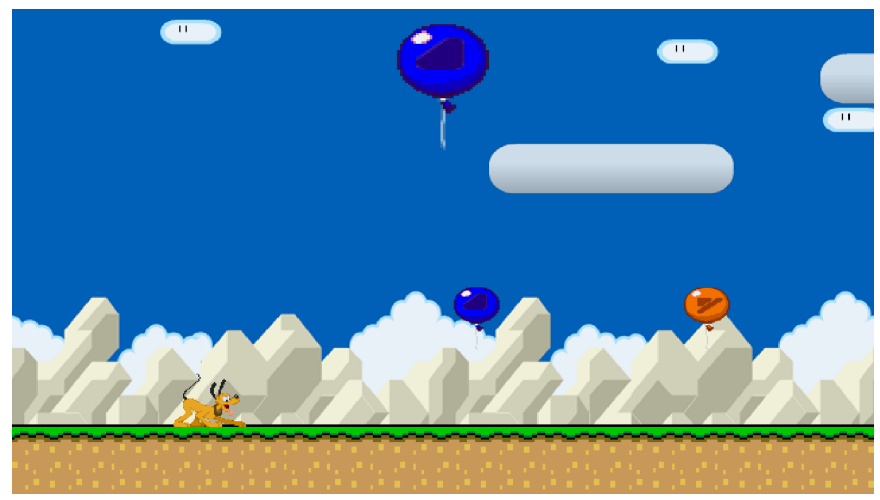

Figura 3 - Tela do aplicativo com o Pluto feliz

Existem também a possibilidade da criança errar e com isso o Pluto fica triste como mostra a figura 4 :

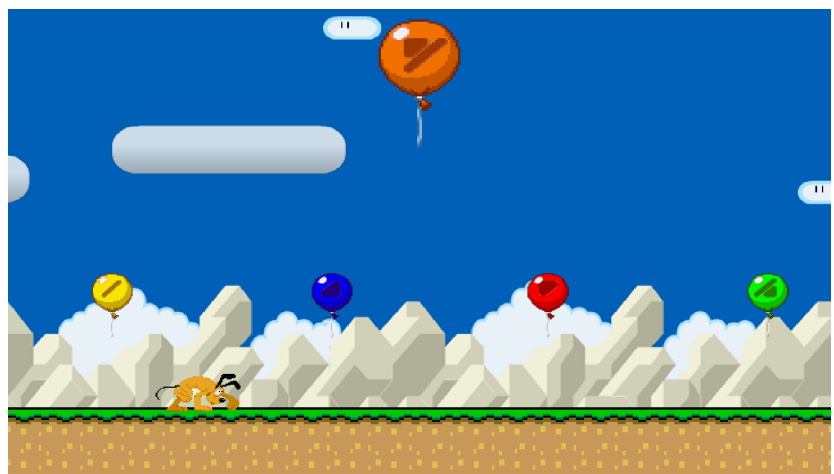

Figura 4 - Tela do aplicativo com o Pluto feliz 
O jogo utiliza de elementos como Sprint para realizar a animação tanto do Pluto como dos balões. O jogo também conta com as animações do balão estourando e de sons do mesmo, como o jogo foi desenvolvido não somente para os daltônicos, mas para crianças em geral com deficiência ou não, o jogo conta com som, animação e musicas que entretêm a criança.

Como pode ser visto nas figuras anteriores os balões contam com os mesmo símbolos que são utilizados no projeto ColorADD de Miguel Neiva. Estes símbolos como explicado anteriormente ajudam o daltônico ou qualquer pessoa a ver as cores em formato de símbolos, estes elemento são usados para ensinar as crianças daltônicas as cores de forma simples e de fácil memorização.

\section{CONCLUSÃO}

Existe varias abordagens que podem ser utilizadas para o ensinamento das cores para as crianças. O propósito deste trabalho é mostrar uma abordagem mais simples e lúdica de ensinar cores tanto a crianças daltônicas como qualquer criança. $\mathrm{O}$ próximo passo será testar a aplicação com crianças daltônicas e com crianças que não possui essa deficiência.

\section{REFERÊNCIAS}

Carletto, A. C., Cambiaghi, S. "Desenho Universal: um conceito para todos".

Hotyat, F (1978) "Psicologia da criança e do adolescente". Coimbra: Livraria Almedina.

Frank C. B. Junior; Oliveira, I. P.; Sales, L.; Souza, R. (2011) "Signos de Trânsito pelos portadores de Daltonismo". $15^{\circ}$ ERGODesing. In http://pdf.blucher.com.br/designproceedings/15ergodesign/202-U048.pdf

Melo, D.G., Galon, J. E. V., Fontanella. B. J. B. (2014) "Os Daltônicos e suas dificuldades: condições negligenciadas no Brasil" In: http://www.scielo.br/pdf/physis/v24n4/0103-7331-physis-24-04-01229.pdf

Miguel N. (2014) “Projeto ColorADD”. In http://www.coloradd.net/

Papalia, D.; Olds, S.; Feldman, R.(2001) “O Mundo da Criança. Megraw Hill”

Sprints(2014) "Sprint database” In http://spritedatabase.net/

Vieira, J. (s/d) "O Desenvolvimento cognitive" in http://www.filosofianaesen.com, [s/d].

The New York Times - Color blindness is the inability to see certain colors in the usual way. Disponível em: http://www.nytimes.com/health/guides/disease/colorblindness/overview.html 